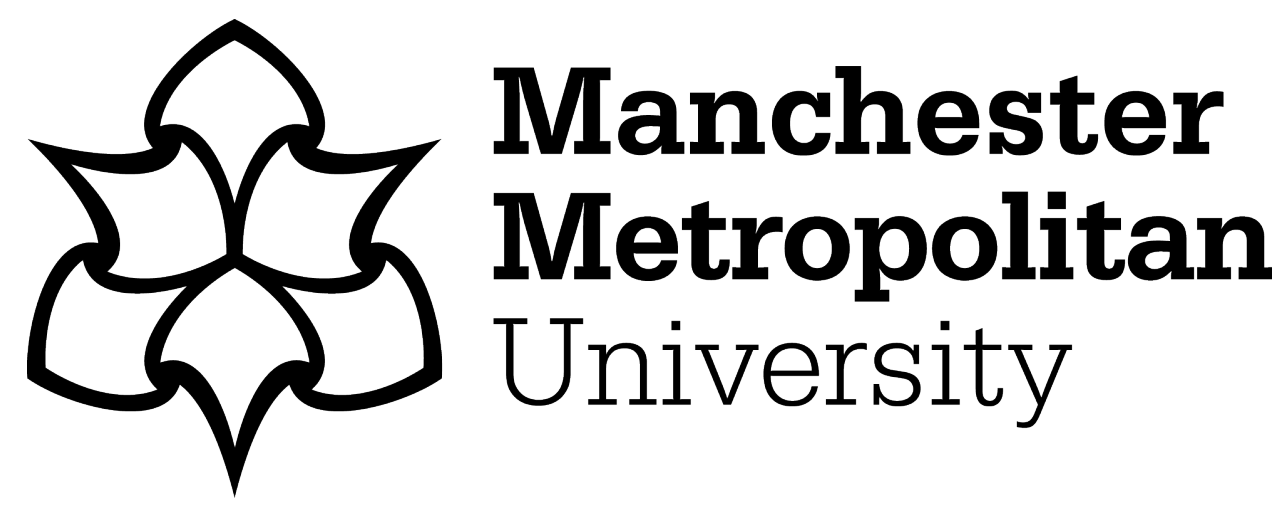

Ireland, A, Rittweger, J and Degens, Hans (2014) The influence of muscular action on bone strength via exercise. Clinical Reviews in Bone and Mineral Metabolism, 12 (2). pp. 93-102. ISSN 1534-8644

Downloaded from: https://e-space.mmu.ac.uk/621399/

Version: Accepted Version

Publisher: Springer

DOI: https://doi.org/10.1007/s12018-013-9151-4

Please cite the published version 


\title{
THE INFLUENCE OF MUSCULAR ACTION ON BONE STRENGTH VIA
} EXERCISE

\author{
Alex Ireland $^{1}$, Jörn Rittweger ${ }^{2}$, Hans Degens ${ }^{1}$
}

1. Cognitive Motor Function Research Group, Manchester Metropolitan University, John Dalton Building, Chester Street. Manchester, M1 5GD, United Kingdom.

2. Institute of Aerospace Medicine, German Aerospace Centre, Linder Höhe 1, D-51147, Cologne, Germany.

Corresponding Author details: Alex Ireland, Manchester Metropolitan University, John Dalton Building, Chester Street. Manchester, M1 5GD, United Kingdom. Tel: 0044161247 1987, Fax: 0044161247 5751, Email: a.ireland@mmu.ac.uk. 
Abstract: Mechanical stimuli influence bone strength, with internal muscular forces thought to be the greatest stressors of bone. Consequently, the effects of exercise in improving and maintaining bone strength have been explored in a number of interventional studies. These studies demonstrate a positive effect of high-impact activities (i.e. where large muscle forces are produced) on bone strength, with benefits being most pronounced in interventions in early pubertal children. However, current studies have not investigated the forces acting on bones and subsequent deformation, preventing the development of optimized and targeted exercise interventions. Similarly, the effects of number and frequency of exercise repetitions and training sessions on bone accrual is unexplored. There are conflicting results as to gender effects on bone response to exercise, and the effects of age and starting age on the osteogenic effects of exercise are not well known. It also appears that exercise interventions are most effective in physically inactive people, or counteracting conditions of disuse such as bed rest. Bone strength is only one component of fracture risk, it may be that exercise resulting in improvements in e.g. muscle force/power and/or balance are more effective than those whose effects are solely osteogenic. In summary, exercise is likely to be an effective tool in maintaining bone strength but current interventions are far from optimal.

Keywords: Bone, BMD, Muscle, Exercise, Osteoporosis 


\section{Introduction}

It is no longer in doubt that mechanical stimuli (or their absence) have an effect on bone [1]. Evidence for this include the increase and decrease of functionally isolated in vivo avian bone mass in response to unloading and loading, respectively [2] and the loss of bone mass after bed rest [3] or spaceflight [4]. Harold Frost's Mechanostat [5] is the current prevailing theory on bone adaptation to mechanical stimuli, which proposes that bone adaptations serve to keep habitual bone strain within defined thresholds. However, the origin of these mechanical stressors is not encompassed within the theory.

\begin{tabular}{|c|c|c|}
\hline & Standing & Hopping \\
\hline Body Mass [kg] & 70 & 70 \\
\hline Ground reaction force $[\mathrm{kN}]$ & 0.7 & 2.5 \\
\hline Torque [Nm] & 84 & 300 \\
\hline Acceleration [g] & 1 & 3 \\
\hline Force $_{\text {AchillesT }}[\mathrm{kN}]$ & 2.1 & 7.5 \\
\hline Force $_{\text {Tibia }}[\mathrm{kN}]$ & 2.8 & 10 \\
\hline
\end{tabular}

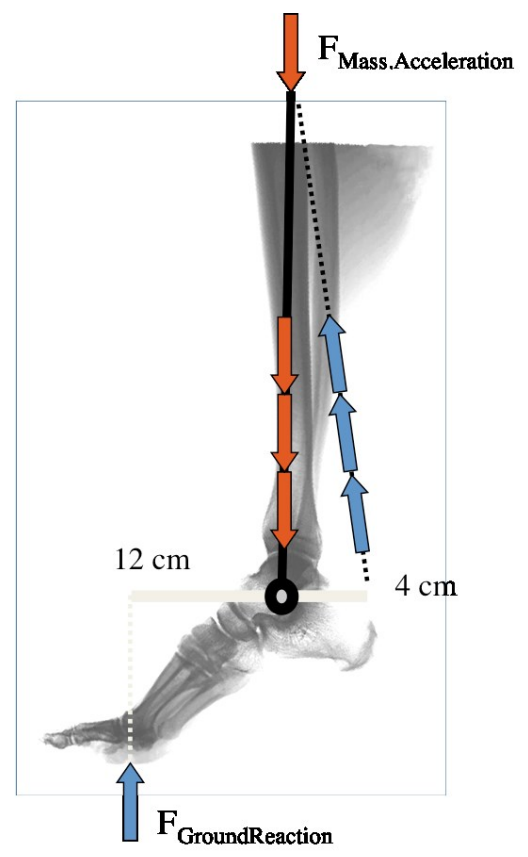

Figure 1. Reaction and tendon forces during standing and hopping. Reproduced with permission from [8].

Ground reaction forces are important stressors of bones of the lower extremities and vary greatly dependent on the type of physical activity undertaken. Walking results in ground reaction forces roughly equal to body mass [6], whereas peak ground reaction forces of up to 15 times body mass have been recorded during the step phase of a triple jump [7]. However, given the short levers that muscles work against, internal muscular forces (often produced in reaction to an applied external load) must be expected to substantially exceed the external loads applied. For example, Achilles tendon force during standing and hopping is approximately three times greater than the ground reaction force [8] (Figure 1) - this disparity can be even more pronounced in other limb segments dependent upon the length of the moment arm. Provided that bone strength is governed by peak strains it should be maximal muscle force that dictates the influence of the muscle on bone. Given that muscle mass and power or force generating capacity are normally correlated it is not surprising then that not only have close relationships between maximal muscular strength and power and bone strength been found [9, 10], but also between muscle mass (as a surrogate for maximal force) and bone size, mass or strength. These associations have been found 
in children and adolescents [11], adults and older individuals [12], and even in spinal cord injury patients that suffer from extreme disuse [13]. The distinctly different muscle:bone relationships within the two arms of tennis players suggest, however, that muscle mass may be too simple a proxy to accurately describe the influence of muscle on bone [9]. In addition, the temporal nature of the relationship between muscle and bone (i.e. changes in muscle (the stressor) should precede those in bone) has been well demonstrated in several studies. For example, in the case of a woman suffering cruciate ligament injury, the instantaneous loss of muscle force upon ligament rupture preceded a delayed reduction in bone strength (Figure 2) [14] and the increase in muscle strength during rehabilitation preceded the return of BMD to pre-injury values. Also during the pubertal growth spurt the peak rate of lean body mass accrual precedes peak bone mass accrual rate [15]. Besides the direct influences of muscular loading on bone, muscle and bone strength may also be linked through common endocrine signaling pathways $[16,17]$.

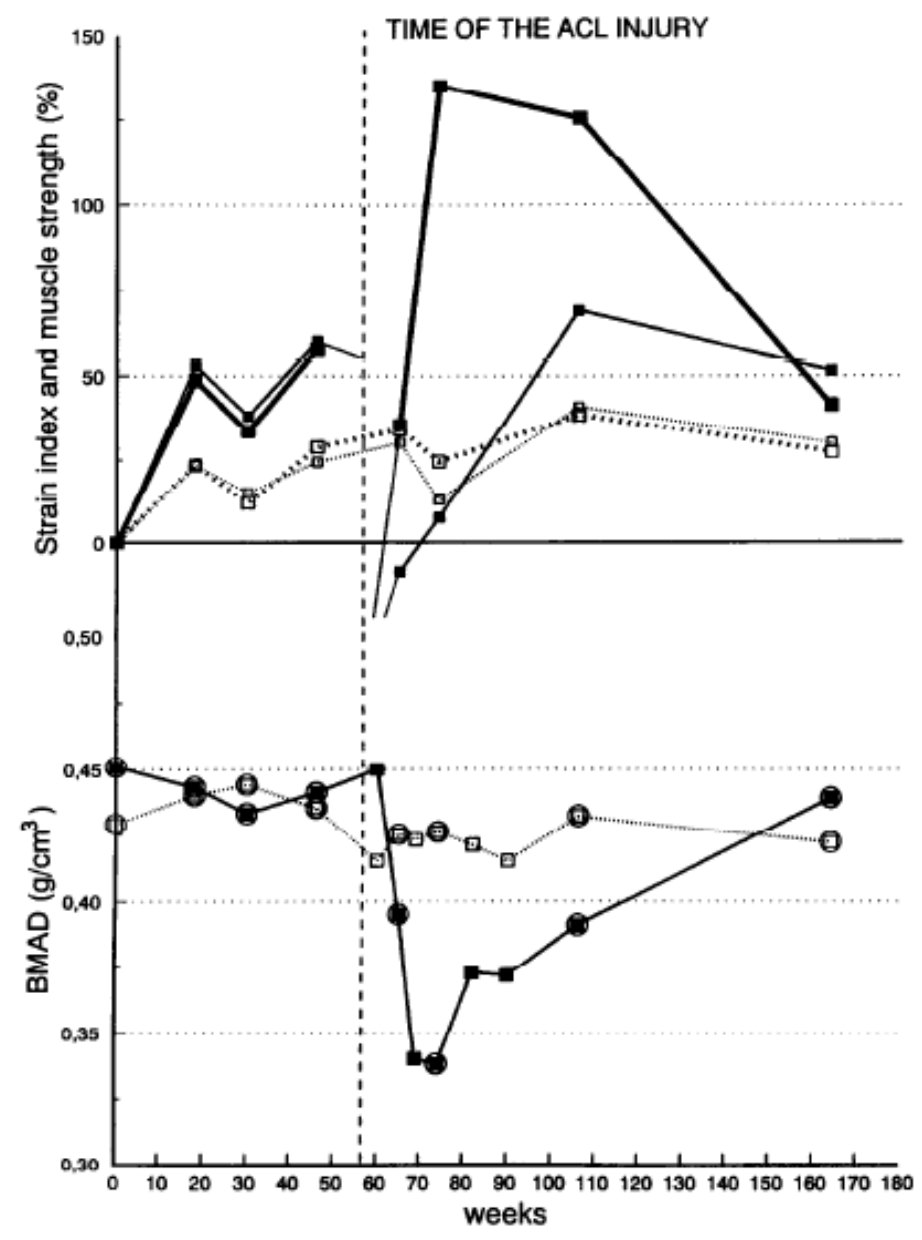

Figure 2. Time course of changes in strain index, muscle strength and patellar bone mineral density following anterior cruciate ligament (ACL) injury and subsequent rehabilitation. Upper panel: wide solid line indicates injured limb strain index, narrow solid line indicates isometric strength - wide and narrow dotted lines indicate respective values in the unaffected limb. Lower panel: solid and dotted lines indicate patellar aBMD in the injured and unaffected limbs respectively. Reproduced with permission from [14]. 
If indeed maximal strains govern bone adaptation and internal muscle forces are the dominant effectors of bone strain, then maximal muscle force should determine the osteogenic potential of an exercise modality. Therefore, according to Hill's muscle model [18] exercise involving eccentric contractions at high rates of muscle lengthening should result in the highest forces and hence largest bone adaptations. Such contractions occur during sudden application of a large external force, as in what are known as high-impact exercise modalities such as sprinting or jumping [19]. In support of the significance of high-impact exercise modalities is the greater femoral bone strength in athletes who regularly train in these sports than sedentary controls, whereas in athletes in sports without an impact element (e.g. swimming and cycling) there was no such effect on femoral bone strength [20]. This association of high peak force with bone adaptation is also demonstrated in master athletes of different locomotory disciplines (e.g. race walking, long/middle distance running and sprinting) - whereby tibial bone strength is positively associated with the speed of the event (and hence the magnitude of ground and presumably muscular forces) [21]. In

addition, differences between athletes and controls follow site-specific patterns -

greater bone strength in epiphyseal areas resulting from greater bone mineral density and bone cross-sectional area, whereas differences in diaphyseal bone strength are a result of greater bone area and differing geometry (larger periosteal/endocortical circumferences) but not bone density [22]. It is possible, however, that part of these differences between athletes and non-athletes is a result of self-selection bias. The largest adaptations thought to be attributable to exercise alone are those in the racquet arm of tennis players - distal radius and mid-humerus bone mass being $45 \%$ greater in adolescent boys' favoured arm than the contralateral limb, these side differences being 10-20 times greater than those found in sedentary males [9, 23]. In addition, these side differences follow the same site-specific pattern as outlined above.

Considering the dominating influence that physical activity has on bone strength parameters, it is not surprising that a large number of studies have been conducted to investigate the effects of controlled exercise interventions on bone. A difficulty in comparing these studies is the use of either pQCT or DEXA to measure bone strength indicators. pQCT offers several advantages over DEXA analysis - cortical and trabecular bone can be analysed separately, bone geometry can be examined and volumetric bone density is given (rather than a 2D areal bone density measure which is influenced by bone size). However, pQCT cannot examine proximal limb segments (e.g. femoral neck) or axial bone (such as the spine).

\section{Exercise in children and adolescents}

Size and strength of both bone and muscle change greatly with age - adult bone and muscle mass being 4-5 times greater than that of young children [24]. Whilst there is a strong association of bone mass and height (and hence long bone length) the size and mass of bone cross-sections also greatly increases - young adult distal tibial bone mass being around 10 times greater than bone mass at birth $[25,26]$. Puberty is associated with pronounced bone accrual - bone mass more than doubles in females and nearly triples in males between the ages of 8 and 18 [27], with peak bone accrual 
rate occurring at $\sim 12$ years of age in females and $\sim 14$ years in males [15]. Changes in bone length and mass do not occur synchronously during puberty, with peak height velocity preceding peak bone mass accrual by around 9 months (and peak lean mass accrual rate by around six months, with these peak differences more pronounced in females [15]. Longitudinal bone growth occurs at the metaphyses, and during rapid growth (such as during puberty) a less pronounced age gradient in metaphyseal bone occurs (Figure 3) [28]. This results in much younger, weaker bone at these sites, and may well be a contributing factor (together with asynchronous muscle:bone development) to the increased incidence of long bone fracture during early puberty [29].
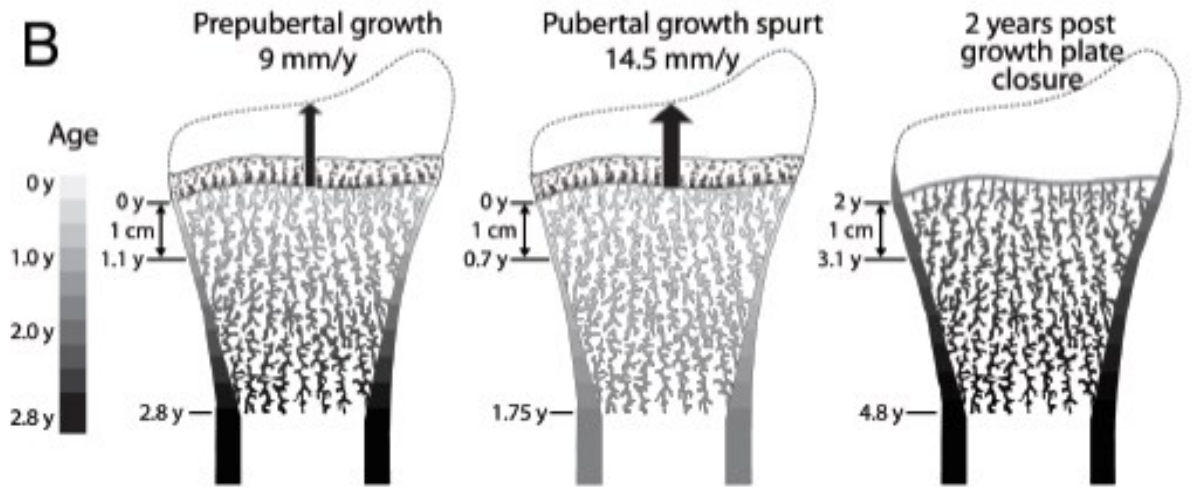

Figure 3. Effect of growth rate on the age gradient in metaphyseal structure. For the 'prepubertal growth' and 'postpubertal growth spurt' scenarios, the simplifying assumption is made that the entire metaphysis has been built under the conditions of the indicated growth rate. The 'post growth plate closure' situation assumes that the speed of growth is constant $9 \mathrm{~mm} /$ year and then abruptly decreases to zero. Note that 'age' in this context refers to the time that has passed since the growth plate metaphysis border has moved across a given location. Modified and reproduced with permission from [28].

This period of rapid bone growth has been identified as a window of opportunity to obtain a high peak bone mass, with the potential exercise benefits of bone thought to be limited after puberty $[30,31]$ or epiphyseal closure $[32,33]$. In line with this, a large number of interventional exercise studies have been completed in the young with positive effects on bone found in a number of studies - particularly those involving early pubertal children [34]. Whilst the magnitude of exercise benefits varies greatly between studies, the most effective interventions led to $5-10 \%$ greater bone mass or density gains than observed in controls $[35,36]$. A problem for the interpretation of many of these studies is the multi-modal nature of interventions, incorporating activities as diverse as weight training, ball sports and isolated jumping exercises within the same programme - making it impossible to isolate the effectiveness of individual exercise modalities. However, jumping exercises are a common component of the most successful interventions, and even jumping exercises alone were effective in improving bone strength [36, 37] - while no such effect was found for resistance exercise [38]. Ground reaction force (GRF) data (as a surrogate for bone loading) was not collected in all studies - however, within those which 
reported values the study with the highest recorded GRF ( $\sim 9$ times bodyweight) also recorded the most marked positive effects on bone strength [36].

A number of jumping intervention studies incorporating pQCT measurements of tibial bone have been conducted in children and adolescent populations. In contrast to findings in DXA-based studies, no significant effects of exercise were found in bone measures between exercising children and controls [39-42]. The exception to this was a greater periosteal and endocortical circumferences in exercising children in one study [40], although only one other study reported these geometrical parameters [42]. However, the effects of exercise on bone are site-specific - it may be that jumping exercise preferentially affects areas such as the femoral neck and lumbar spine (measurable with DEXA) rather than sites commonly measured by pQCT, such as the tibia.

In additional to controlled intervention trials, there are many studies investigating differences between exercising children and control counterparts - although these are likely subject to selection bias on the part of participants. Girls of 4-8 years of age who selected to start gymnastics classes gained 3.3\% greater forearm bone mass and $2.2 \%$ greater lumbar spine BMD in the following 24 months than non-exercising controls [43]. The effects of starting age on benefits in bone have also been examined in tennis players. Those who began playing prior to menarche had 2-4 times greater side differences in bone strength (in favour of the racquet arm) than those who began more than 15 years after menarche [44]. Similarly, pubertal stage was found to affect responses in bone geometry to exercise in tennis players [45]. However, as yet it is unclear whether it is end of puberty or epiphyseal closure at which the periosteal expansion in response to exercise is attenuated.

\section{Exercise in adulthood}

The so-called 'peak bone mass' (PBM) occurs in the second or third decade, with age at peak bone mass being site specific [46, 47]. The determinants of PBM are still unclear, and it seems that its relevance has been over-exaggerated in the past, given that there seems to be very little, if any, age-related losses from the tibia [48, 49], and that immobilization-induced losses are readily recovered, at least in adulthood [50]. By comparison with child and adolescent studies, there are few interventional exercise studies in young adult populations. Exercise interventions generally resulted in bone accrual compared to controls, albeit less pronounced (1-3\%) than in children and adolescents. However, resistance training was effective in premenopausal females [51] (in contrast to findings in children), which may relate to reduced physical activity in adulthood, hence similar exercise represents a greater departure from habitual loading in premenopausal women than in children. That exercise interventions may be more effective in participants with lower pre-intervention activity levels is supported by findings from a controlled intervention in monozygotic twins that exercise only resulted in significant bone accrual when participants were not already regular exercisers [52]. The lack of pQCT-based controlled intervention studies in this age group prevents analysis of any effects on bone geometry following end of puberty/epiphyseal closure.

It is important to know whether any exercise-induced benefits on bone can be maintained after cessation of regular exercise. Exercise benefits in racquet arm bone 
of female adult tennis and squash players were found to be well-maintained despite a $70 \%$ reduction in training volume [53]. Results of comparisons of bone strength in retired gymnasts [54], weightlifters [55, 56] and ballet dancers [56] with non-athletic controls are mixed - however these studies are more likely to be subject to a selfselection bias. Similarly, the volume of exercise required to improve bone strength is an important consideration when planning exercise interventions - bone strength in adult women improved following an intervention in which they completed only 10 jumps three times a week [57].

\section{Exercise in older age}

Ageing is associated with loss of muscle mass and concomitant loss of force and power generating capacity. Whilst muscle atrophy is a factor in strength loss, other neuromuscular and tendinous changes contribute significantly [58]. Firstly neural factors such as reduced neural activation, loss of motor units [59] and more pronounced denervation of fast motor units [60]. Muscular factors including changes in muscle architecture [61], decreased muscle fibre shortening velocity and specific tension [62, 63], whilst decreased tendon stiffness [64] may also contribute. In addition, there is some evidence that the mechanosensivity and osteogenic response of bone cells to strain diminishes with age [65-67].

Given that the greatest stressor of bone (muscular forces) declines with age and that older bone also seems less responsive to mechanical stimuli, bone strength may decrease with age. Indeed, whilst bone size continues to increase slightly with age, more sizeable age-related reductions in BMD suggest that bone strength is reduced in older age [49]. Accordingly, the incidence of osteopenia and osteoporosis (defined by the World Health Organisation as BMD more than one, and more than two-and-a-half standard deviations lower respectively than mean values in 30 year olds) increases with age as does risk of bone fracture [68]. However, these age effects may be sitespecific - hopping force appears to decline little with age [69], as does tibial bone mass [48].

In comparison to studies in children and younger adults, there are quite a number of pQCT-based studies investigating the effects of exercise interventions on bone strength in older people [70]. This should allow analysis of effects of exercise on bone geometry. Unfortunately with few exceptions [71] relevant parameters such as endocortical or periosteal circumferences are not reported. Whilst effects of exercise interventions are mixed, the effects of high-impact exercise such as jumping and volleyball $[72,73]$ are most pronounced. The gains or attenuated rate of bone strength loss are similar (1-3\%) to those found in interventions in young adult women. The effects of low-impact exercise are mixed; whilst tai chi training was found to have a beneficial effect in reducing the rate of bone loss [74], benefits of resistance/vibration training are less pronounced or absent $[71,75]$.

Physical activity levels decrease with age [76], hence the exercise stimulus required to stimulate osteogenesis may be less in older people. There are few studies reporting the effects of exercise on bone in older men - however, a hopping intervention was found to increase bone area $2.4 \%$ and bone mass $1.3 \%$ relative to controls [77], with similar results found in women [78]. There are likewise few studies comparing effects of similar interventions on bone strength in people of different ages - 
however, bone density in premenopausal women increased significantly more than in postmenopausal women as a result of a jumping exercise intervention (despite ground reaction forces during exercise in the postmenopausal women being 33\% greater relative to bodyweight) [79]. Master athletes are known to have greater bone strength than age-matched controls, with the magnitude of advantage in bone strength related to running/walking speed of their chosen event [21]. However, this advantage appears to diminish with age [48].

\section{Exercise in men and women}

Sexual differentiation also has an effect on bone strength. Whilst sex-dependent differences are not evident at birth [80], by 14 months bone mass and size are significantly greater in boys than girls [26]. This persists into adulthood where, even when body size is controlled for men have greater bone strength than women [49]. During puberty, extra bone mineral deposition on the endocortical surface and in trabecular bone areas in females (thought to be required to help meet the demands of pregnancy and lactation) results in a higher bone mineral to lean mass ratio than in males [81]. This extra mineral is lost upon estrogen withdrawal, e.g. after child birth or menopause $[82,83]$ primarily in trabecular bone, and thus likely contributing to post-menopausal fractures. Male osteoporosis rates also increase with age, and the two sexes experience similar mechanisms of bone loss, being driven by increases in osteoclast activity rather than reduction of bone formation by osteoblasts [84].

There are a limited number of studies which examine the effects of similar exercise interventions in men and women. Exercise benefits in older men and women following a hopping intervention were similar [77, 78], as were those found in boys and girls following the same school-based exercise intervention [85, 86]. However, hip BMD in boys but not girls was found to be related to levels of physical activity in a cross-sectional study [87] and male adolescent tennis players were found to have greater side differences in bone strength than females of similar age and training volume [9]. In contrast, side differences in adult tennis players were found to be similar regardless of gender [88]. It has been suggested that estrogen affects bone mechanosensitivity [89] - this may explain these dischordant sex differences between groups of different age/maturity.

\section{Discussion and perspective}

In conclusion, exercise interventions have the potential to greatly improve bone strength - particularly in children. However, it is clear that as yet this potential is relatively unexplored. At the most basic level, it is unclear which modalities of exercise are most beneficial for bone strength. This review has focused on traditional exercise interventions (running, jumping, resistance training, etc.) for which controlled intervention trial data exists. It may be that new (or even yet to be invented) exercise modalities may be more efficient at improving and maintaining bone strength. For example, whole body vibration (WBV) training has attracted research interest over the past decade. As it may not require as much voluntary effort on the part of the participant, it could be an effective way of encouraging participation in those not keen on traditional exercise. Perhaps more importantly, it will also be applicable to those with movement restrictions ranging from bed rest to spinal cord injury. At present studies on the impact of vibration exercise on bone are often limited 
by e.g. cohort size [90] and the combination with resistance training [91] which make it difficult to assess the benefits of vibration exercise per se. Whilst some positive effects of WBV on bone strength in ambulatory children and adults have been found [75] they are quite small. Therefore it may be that WBV training is most effective in those with restricted movement capabilities. Observational studies report that bone strength in the lower and upper limbs is greatest in sprinters and tennis/squash players $[9,21,93]$ - however these sports (or even modified variants) have not been used in interventional studies. In fact, not a single high-impact exercise intervention study in the upper limbs has been completed - despite prevalence of upper and lower limb bone fractures being similar [68].

It should be possible to identify or design exercise actions that cause large amounts of strain to occur at clinically desirable sites (i.e. those where fracture incidence is high) such as the femoral neck, distal radius and proximal humerus. However, a number of other factors will contribute to effectiveness of an exercise programme and are currently unknown in humans. Recovery periods between repetitions of an exercise and between exercise bouts have been shown to greatly affect bone formation rates. In rat studies, allowing $14 \mathrm{~s}$ of recovery between exercise repetitions resulted in $66-190 \%$ greater bone formation rate compared to shorter recovery periods - similarly, after 8 hours between bouts mechanosensitivity was restored (compared to a 50\% decrement in shorter recovery times). In addition, mechanosensivity of bone decreases after a small number of loading cycles with bouts in excess of 36 cycles having no additive effect on avian ulnae adaptation [2]. Similarly, 5 jumps per day increased bone strength in rats, with diminishing improvements in bone strength gains with increased numbers of jumps [94]. Loading magnitude and frequency also appear to interact - as magnitude of loading increases, the number of loadings required to elicit a bone response diminishes [95]. In adult women only 10 jumps three times a week was enough to result in significant improvements in bone strength [57] - but the threshold for bone adaptation may be even lower than this amount. The effect of training frequency has also been examined - with postmenopausal women completing daily hopping exercise accruing greater benefits in bone density than non-exercisers or participants who exercised less frequently [78]. An interaction of exercise by nutrition was revealed in studies including both exercise ( 3 x 20 min jumping exercise per week) and nutritional (calcium supplementation) interventions - highlighting the importance of adequate nutrition in the ability to maximize the osteogenic potential of exercise [96, 97]. In addition to nutritional influences, hormonal effects on exercise efficacy for bone health have been found bone strength being lower in amenorrheic athletes compared to healthy athletes and controls [98]. Bone adaptation appears - at least from observational and within-subject models - to be site-specific, with epiphyseal and diaphyseal adaptations following distinctly different patterns $[9,22,23]$. However, due to the preference for DEXA-based scanning in intervention studies (and incomplete reporting of pQCT-obtained values in other studies) the effects of exercise interventions in the two sites are unclear. As the majority of fractures occur in epiphyseal areas of bone [68], these site differences in bone adaptation would seem to be of key clinical importance.

Fracture incidence is multi-factorial, and bone strength is certainly associated with fracture risk [68]. However, fracture incidence is strongly related to incidence of falls independent of bone strength [99] - fall incidence hence relates also to balance and hence the muscular and tendinous factors discussed previously as well as e.g. agerelated decrease in procrioception [100]. Another useful factor that could be 
considered for inclusion within exercise interventions aimed at bone health could be measures such as balance or co-ordination. Exercise is effective in reducing incidence of falls and risk of falling, whereas other interventions (e.g. nutritional and home safety interventions) have not been proven to be effective [101].

Although peak forces acting on bones are thought to determine their structure, few intervention studies report these forces as measured during exercise, and it is entirely unknown what kind of deformation modes these forces engender in exercising human bones. The few available studies report ground reaction forces, neglecting even calculated values (as opposed to direct tendon measurement) of the internal muscle forces. Indeed, comparison of these reaction forces between different studies may not represent even relative differences between exercise modalities. Due to several factors such as tendon compliance, pre-activation of the muscle and rate of force development the time course of bone loading by muscle (via the tendon) and by external forces may differ. For instance, during walking two peaks in ground reaction force are normally seen, where Achilles tendon force only shows a single peak [102]. Similarly, calculated ankle joint forces peak prior to 'toe-off' (i.e. relating to the peak Achilles tendon force) rather than heel-strike that might have been expected [103]. Inter-joint differences in muscular loading in reaction to applied external forces may also differ temporally - loading patterns in achilles tendon and patellar tendon differ during squat and counter-movement jumping [104]. Future research therefore must try to identify the exact loading and deformation modes of bones during exercise, so that optimized and targeted exercise prescriptions can be developed.

The physical status of intervention participants may also affect the benefit accrued. For instance, exercise intervention in monozygotic twins was only effective in twins who did not already participate in high-impact sports [52]. Analogous to this are the observations that exercise is most effective in conditions of disuse - e.g. $30 \%$ of bone lost following spinal cord injury was recovered following 24 weeks of daily electrical stimulation of muscle [105], and that resistive exercise largely prevented bone loss during bed rest [91]. This is promising as it may mean that physically inactive or frail participants may in fact have a good response of bone to exercise. This is particularly pertinent when we consider that frailty is associated with much higher rates of falling, fractures and mortality [106].

However, the pursuit of high bone mass has previously been questioned [107], as - for instance - higher bone mass in older men is associated with greater incidence of osteoarthritis [108]. It may be that impact loading causes osteoarthritis - firstly, directly through an increased rate of incident osteoarthritis [109]. Alternatively, it has been suggested that resulting higher bone mass and increased bone stiffness could indirectly lead to progression of the disease [110]. These negative effects may well be ameloriated by exercise during growth - when bone size seems more responsive to exercise [111], hence reducing joint stress. Alternatively, those with low bone mass and strength may not be at as great a risk from these complications if the effect of exercise interventions are to improve their bone strength to 'normal' levels.

Compliance is another important issue when designing exercise intervention programs to improve bone health. Drop-out and compliance rates vary greatly between studies - the former being as high as 67\% in children [86], although withdrawal of school and teacher support greatly affected this value. Across adult studies, retention rates from exercise 
groups is $79 \%$ with compliance to exercise during the interventions averaging $76 \%$ [112] - this is much higher than adherence to pharmacological interventions targeting osteoporosis [113]. In addition, men and older participants (as well as postmenopausal women) were found to have greater adherence rates. Conversely, high-intensity training and unsupervised training are associated with lower compliance rates. After all, it is quite naturally difficult to motivate people to exercise just for the sake of their bones when the goal fracture prevention is equally abstract and remote. Future exercise interventions thus should either involve a greater 'fun' component, or use other secondary incentives in order to engage test subjects or patients.

In summary, exercise is a likely method of improving and maintaining bone strength throughout lifespan. However, current interventions are likely far from optimal as amongst other factors - the effects of different exercise modalities and volume/intensity of training have not been identified. In addition, due to the lack of pQCT or MRI-based studies the site-specific effects of exercise interventions and effects on bone geometry are not well known. Further studies investigating effects of different exercise modalities, bout timing and program design are required to improve the efficacy of exercise-based interventions aimed at improving bone health. In addition, study of age/maturity and sex-related differences in bone adaptation - as well as differential response based on habitual physical activity levels - may reveal important information pertaining to the personalization of exercise programmes for individuals.

Declarations: The authors all declare no conflict of interest relating to their work on this paper.

\section{$\underline{\text { References: }}$}

[1] Turner CH. Skeletal Adaptation to Mechanical Loading. Clinical Reviews in Bone and Mineral Metabolism 2007;5: 181-194.

[2] Rubin CT, Lanyon LE. Regulation of bone formation by applied dynamic loads. J Bone Joint Surg Am 1984;66: 397-402.

[3] Rittweger J, Felsenberg D. Recovery of muscle atrophy and bone loss from 90 days bed rest: results from a one-year follow-up. Bone 2009;44: 214-24.

[4] Lang T, LeBlanc A, Evans H, Lu Y, Genant H, Yu A. Cortical and trabecular bone mineral loss from the spine and hip in long-duration spaceflight. J Bone Miner Res 2004;19: 1006-12.

[5] Frost HM. The mechanostat: a proposed pathogenic mechanism of osteoporoses and the bone mass effects of mechanical and nonmechanical agents. Bone Miner 1987;2: 73-85.

[6] Keller TS, Weisberger AM, Ray JL, Hasan SS, Shiavi RG, Spengler DM. Relationship between vertical ground reaction force and speed during walking, slow jogging, and running. Clin Biomech (Bristol, Avon) 1996;11: 253-259.

[7] Perttunen JO, Kyrolainen H, Komi PV, Heinonen A. Biomechanical loading in the triple jump. J Sports Sci 2000;18: 363.

[8] Rittweger J. Physiological Targets of Artificial Gravity: Adaptive Processes in Bone and Artificial Gravity. In: Clement G, Bukley A, editors. Artificial Gravity. Berlin: Springer; 2007, p. 191-231.

[9] Ireland A, Maden-Wilkinson T, McPhee J, Cooke K, Narici M, Degens H, Rittweger J. Upper Limb Muscle-Bone Asymmetries and Bone Adaptation in Elite Youth Tennis Players. Med Sci Sports Exerc 2013;45: 1749-58. 
[10] Ashe MC, Liu-Ambrose TY, Cooper DM, Khan KM, McKay HA. Muscle power is related to tibial bone strength in older women. Osteoporos Int 2008;19: 1725-32.

[11] Schoenau E, Neu CM, Beck B, Manz F, Rauch F. Bone mineral content per muscle cross-sectional area as an index of the functional muscle-bone unit. J Bone Miner Res 2002;17: 1095-101.

[12] Ferretti JL, Capozza RF, Cointry GR, Garcia SL, Plotkin H, Alvarez Filgueira ML, Zanchetta JR. Gender-related differences in the relationship between densitometric values of whole-body bone mineral content and lean body mass in humans between 2 and 87 years of age. Bone 1998;22: 683.

[13] Bass SL, Eser P, Daly R. The effect of exercise and nutrition on the mechanostat. J Musculoskelet Neuronal Interact 2005;5: 239-54.

[14] Sievanen H, Heinonen A, Kannus P. Adaptation of bone to altered loading environment: a biomechanical approach using X-ray absorptiometric data from the patella of a young woman. Bone 1996;19: 55-59.

[15] Rauch F, Bailey DA, Baxter-Jones A, Mirwald R, Faulkner R. The 'musclebone unit' during the pubertal growth spurt. Bone 2004;34: 771-5.

[16] Zofková I. Hormonal aspects of the muscle-bone unit. Physiol Res 2008;57 Suppl 1: S159-69.

[17] Cianferotti L, Brandi ML. Muscle-bone interactions: basic and clinical aspects. Endocrine 2013.

[18] Hill A. The Heat of Shortening and the Dynamic Constants of Muscle. 1938.

[19] Sousa F, Ishikawa M, Vilas-Boas JP, Komi PV. Intensity- and musclespecific fascicle behavior during human drop jumps. J Appl Physiol 2007;102: 382-9.

[20] Nikander R, Sievanen H, Heinonen A, Kannus P. Femoral neck structure in adult female athletes subjected to different loading modalities. J Bone Miner Res 2005;20: 520-8.

[21] Wilks DC, Winwood K, Gilliver SF, Kwiet A, Chatfield M, Michaelis I, Sun LW, Ferretti JL, Sargeant AJ, Felsenberg D, Rittweger J. Bone mass and geometry of the tibia and the radius of master sprinters, middle and long distance runners, race-walkers and sedentary control participants: a pQCT study. Bone 2009;45: 91-7.

[22] Heinonen A, Sievänen H, Kannus P, Oja P, Vuori I. Site-specific skeletal response to long-term weight training seems to be attributable to principal loading modality: a pQCT study of female weightlifters. Calcif Tissue Int 2002;70: 469-74.

[23] Haapasalo H, Kontulainen S, Sievänen H, Kannus P, Järvinen M, Vuori I. Exercise-induced bone gain is due to enlargement in bone size without a change in volumetric bone density: a peripheral quantitative computed tomography study of the upper arms of male tennis players. Bone 2000;27: 351-357.

[24] van der Sluis IM, de Ridder MA, Boot AM, Krenning EP, de Muinck KeizerSchrama SM. Reference data for bone density and body composition measured with dual energy x ray absorptiometry in white children and young adults. Arch Dis Child 2002;87: 341-7; discussion 341-7.

[25] Capozza RF, Feldman S, Mortarino P, Reina PS, Schiessl H, Rittweger J, Ferretti JL, Cointry GR. Structural analysis of the human tibia by tomographic (pQCT) serial scans. J Anat 2010;216: 470-81. 
[26] Viljakainen HT, Korhonen T, Hytinantti T, Laitinen EK, Andersson S, Mäkitie O, Lamberg-Allardt C. Maternal vitamin D status affects bone growth in early childhood--a prospective cohort study. Osteoporos Int 2011;22: 883-91.

[27] Maynard LM, Guo SS, Chumlea WC, Roche AF, Wisemandle WA, Zeller CM, Towne B, Siervogel RM. Total-body and regional bone mineral content and areal bone mineral density in children aged 8-18 y: the Fels Longitudinal Study. Am J Clin Nutr 1998;68: 1111-7.

[28] Rauch F. The dynamics of bone structure development during pubertal growth. J Musculoskelet Neuronal Interact 2012;12: 1-6.

[29] Landin LA. Fracture patterns in children. Analysis of 8,682 fractures with special reference to incidence, etiology and secular changes in a Swedish urban population 1950-1979. Acta Orthop Scand Suppl 1983;202: 1-109.

[30] Khan K, McKay HA, Haapasalo H, Bennell KL, Forwood MR, Kannus P, Wark JD. Does childhood and adolescence provide a unique opportunity for exercise to strengthen the skeleton? J Sci Med Sport 2000;3: 150-64.

[31] Bass SL. The prepubertal years: a uniquely opportune stage of growth when the skeleton is most responsive to exercise? Sports Med 2000;30: 73-8.

[32] Frost H. The Utah Paradigm of Skeletal Physiology Volume II. Athens: ISMNI; 2004.

[33] Rittweger J. Ten years muscle-bone hypothesis: what have we learned so far?--almost a festschrift--. J Musculoskelet Neuronal Interact 2008;8: 174-8.

[34] Hind K, Burrows M. Weight-bearing exercise and bone mineral accrual in children and adolescents: a review of controlled trials. Bone 2007;40: 14-27.

[35] Morris FL, Naughton GA, Gibbs JL, Carlson JS, Wark JD. Prospective tenmonth exercise intervention in premenarcheal girls: positive effects on bone and lean mass. J Bone Miner Res 1997;12: 1453-62.

[36] Fuchs RK, Bauer JJ, Snow CM. Jumping improves hip and lumbar spine bone mass in prepubescent children: a randomized controlled trial. J Bone Miner Res 2001;16: 148-56.

[37] McKay HA, MacLean L, Petit M, MacKelvie-O'Brien K, Janssen P, Beck T, Khan KM. "Bounce at the Bell": a novel program of short bouts of exercise improves proximal femur bone mass in early pubertal children. Br J Sports Med 2005;39: 521-6.

[38] Blimkie CJ, Rice S, Webber CE, Martin J, Levy D, Gordon CL. Effects of resistance training on bone mineral content and density in adolescent females. Can J Physiol Pharmacol 1996;74: 1025-33.

[39] Johannsen N, Binkley T, Englert V, Neiderauer G, Specker B. Bone response to jumping is site-specific in children: a randomized trial. Bone 2003;33: 533-9.

[40] Specker B, Binkley T. Randomized trial of physical activity and calcium supplementation on bone mineral content in 3- to 5-year-old children. J Bone Miner Res 2003;18: 885.

[41] Heinonen A, Sievanen H, Kannus P, Oja P, Pasanen M, Vuori I. High-impact exercise and bones of growing girls: a 9-month controlled trial. Osteoporos Int 2000;11: 1010.

[42] Anliker E, Dick C, Rawer R, Toigo M. Effects of jumping exercise on maximum ground reaction force and bone in 8- to 12-year-old boys and girls: a 9-month randomized controlled trial. J Musculoskelet Neuronal Interact 2012;12: 56-67. 
[43] Laing EM, Wilson AR, Modlesky CM, O'Connor PJ, Hall DB, Lewis RD. Initial years of recreational artistic gymnastics training improves lumbar spine bone mineral accrual in 4- to 8-year-old females. J Bone Miner Res 2005;20: 509-19.

[44] Kannus P, Haapasalo H, Sankelo M, Sievanen H, Pasanen M, Heinonen A, Oja P, Vuori I. Effect of starting age of physical activity on bone mass in the dominant arm of tennis and squash players. Ann Intern Med 1995;123: 27.

[45] Bass S, Saxon L, Daly R, Turner C, Robling A, Seeman E, Stuckey S. The Effect of Mechanical Loading on the Size and Shape of Bone in Pre-, Peri-, and Postpubertal Girls: A Study in Tennis Players. Journal of Bone and Mineral Research 2002;17: 2274-2280.

[46] Matkovic V, Jelic T, Wardlaw GM, Ilich JZ, Goel PK, Wright JK, Andon MB, Smith KT, Heaney RP. Timing of peak bone mass in Caucasian females and its implication for the prevention of osteoporosis. Inference from a cross-sectional model. J Clin Invest 1994;93: 799-808.

[47] Lorentzon M, Mellström D, Ohlsson C. Age of attainment of peak bone mass is site specific in Swedish men--The GOOD study. J Bone Miner Res 2005;20: 1223-7.

[48] Wilks DC, Winwood K, Gilliver SF, Kwiet A, Sun LW, Gutwasser C, Ferretti JL, Sargeant AJ, Felsenberg D, Rittweger J. Age-dependency in bone mass and geometry: a pQCT study on male and female master sprinters, middle and long distance runners, race-walkers and sedentary people. J Musculoskelet Neuronal Interact 2009;9: 236-46.

[49] Riggs BL, Melton Iii LJ, Robb RA, Camp JJ, Atkinson EJ, Peterson JM, Rouleau PA, McCollough CH, Bouxsein ML, Khosla S. Population-based study of age and sex differences in bone volumetric density, size, geometry, and structure at different skeletal sites. J Bone Miner Res 2004;19: 1945-54.

[50] Rittweger J, Felsenberg D. Recovery of muscle atrophy and bone loss from 90 days bed rest: Results from a one-year follow-up. Bone 2009;44: 214-224.

[51] Winters-Stone KM, Snow CM. Site-specific response of bone to exercise in premenopausal women. Bone 2006;39: 1203-9.

[52] Van Langendonck L, Claessens AL, Vlietinck R, Derom C, Beunen G. Influence of weight-bearing exercises on bone acquisition in prepubertal monozygotic female twins: a randomized controlled prospective study. Calcif Tissue Int 2003;72: 666-74.

[53] Kontulainen S, Kannus P, Haapasalo H, Sievänen H, Pasanen M, Heinonen A, Oja P, Vuori I. Good maintenance of exercise-induced bone gain with decreased training of female tennis and squash players: a prospective 5-year follow-up study of young and old starters and controls. J Bone Miner Res 2001;16: 195-201.

[54] Bass S, Pearce G, Bradney M, Hendrich E, Delmas PD, Harding A, Seeman E. Exercise before puberty may confer residual benefits in bone density in adulthood: studies in active prepubertal and retired female gymnasts. J Bone Miner Res 1998;13: 500.

[55] Karlsson MK, Johnell 0, Obrant KJ. Is bone mineral density advantage maintained long-term in previous weight lifters? Calcif Tissue Int 1995;57: 3258.

[56] Khan KM, Green RM, Saul A, Bennell KL, Crichton KJ, Hopper JL, Wark JD. Retired elite female ballet dancers and nonathletic controls have similar bone mineral density at weightbearing sites. J Bone Miner Res 1996;11: 1566. 
[57] Kato T, Terashima T, Yamashita T, Hatanaka Y, Honda A, Umemura Y. Effect of low-repetition jump training on bone mineral density in young women. J Appl Physiol 2006;100: 839-43.

[58] Clark BC, Manini TM. Sarcopenia =/= dynapenia. J Gerontol A Biol Sci Med Sci 2008;63: 829-34.

[59] Verdú E, Ceballos D, Vilches JJ, Navarro X. Influence of aging on peripheral nerve function and regeneration. J Peripher Nerv Syst 2000;5: 191-208.

[60] Faulkner JA, Larkin LM, Claflin DR, Brooks SV. Age-related changes in the structure and function of skeletal muscles. Clin Exp Pharmacol Physiol 2007;34: 1091-6.

[61] Narici MV, Maganaris CN, Reeves ND, Capodaglio P. Effect of aging on human muscle architecture. J Appl Physiol 2003;95: 2229-34.

[62] Morse CI, Thom JM, Reeves ND, Birch KM, Narici MV. In vivo physiological cross-sectional area and specific force are reduced in the gastrocnemius of elderly men. J Appl Physiol 2005;99: 1050-5.

[63] Degens H. Age-related skeletal muscle dysfunction: causes and mechanisms. J Musculoskelet Neuronal Interact 2007;7: 246-52.

[64] Reeves ND. Adaptation of the tendon to mechanical usage. J Musculoskelet Neuronal Interact 2006;6: 174-80.

[65] Kohrt WM. Aging and the osteogenic response to mechanical loading. Int J Sport Nutr Exerc Metab 2001;11 Suppl: S137-42.

[66] Rubin CT, Bain SD, McLeod KJ. Suppression of the osteogenic response in the aging skeleton. Calcif Tissue Int 1992;50: 306-13.

[67] Klein-Nulend J, Sterck JG, Semeins CM, Lips P, Joldersma M, Baart JA, Burger EH. Donor age and mechanosensitivity of human bone cells. Osteoporos Int 2002;13: 137-46.

[68] Schuit SC, van der Klift M, Weel AE, de Laet CE, Burger H, Seeman E, Hofman A, Uitterlinden AG, van Leeuwen JP, Pols HA. Fracture incidence and association with bone mineral density in elderly men and women: the Rotterdam Study. Bone 2004;34: 195-202.

[69] Runge M, Rittweger J, Russo CR, Schiessl H, Felsenberg D. Is muscle power output a key factor in the age-related decline in physical performance? A comparison of muscle cross section, chair-rising test and jumping power. Clin Physiol Funct Imaging 2004;24: 335-40.

[70] Hamilton CJ, Swan VJ, Jamal SA. The effects of exercise and physical activity participation on bone mass and geometry in postmenopausal women: a systematic review of pQCT studies. Osteoporos Int 2010;21: 11-23.

[71] Stolzenberg N, Belavý DL, Beller G, Armbrecht G, Semler J, Felsenberg D. Bone strength and density via pQCT in post-menopausal osteopenic women after 9 months resistive exercise with whole body vibration or proprioceptive exercise. J Musculoskelet Neuronal Interact 2013;13: 66-76.

[72] Uusi-Rasi K, Kannus P, Cheng S, Sievänen H, Pasanen M, Heinonen A, Nenonen A, Halleen J, Fuerst T, Genant H, Vuori I. Effect of alendronate and exercise on bone and physical performance of postmenopausal women: a randomized controlled trial. Bone 2003;33: 132-43.

[73] Karinkanta S, Heinonen A, Sievänen H, Uusi-Rasi K, Fogelholm M, Kannus P. Maintenance of exercise-induced benefits in physical functioning and bone among elderly women. Osteoporos Int 2009;20: 665-74. 
[74] Chan K, Qin L, Lau M, Woo J, Au S, Choy W, Lee K, Lee S. A randomized, prospective study of the effects of Tai Chi Chun exercise on bone mineral density in postmenopausal women. Arch Phys Med Rehabil 2004;85: 717-22.

[75] Slatkovska L, Alibhai SM, Beyene J, Hu H, Demaras A, Cheung AM. Effect of 12 months of whole-body vibration therapy on bone density and structure in postmenopausal women: a randomized trial. Ann Intern Med 2011;155: 668-79, W205.

[76] Caspersen CJ, Pereira MA, Curran KM. Changes in physical activity patterns in the United States, by sex and cross-sectional age. Med Sci Sports Exerc 2000;32: 1601-9.

[77] Allison SJ, Folland JP, Rennie WJ, Summers GD, Brooke-Wavell K. High impact exercise increased femoral neck bone mineral density in older men: a randomised unilateral intervention. Bone 2013;53: 321-8.

[78] Bailey CA, Brooke-Wavell K. Optimum frequency of exercise for bone health: randomised controlled trial of a high-impact unilateral intervention. Bone 2010;46: 1043-9.

[79] Bassey EJ, Rothwell MC, Littlewood JJ, Pye DW. Pre- and postmenopausal women have different bone mineral density responses to the same high-impact exercise. J Bone Miner Res 1998;13: 1805-13.

[80] Viljakainen HT, Saarnio E, Hytinantti T, Miettinen M, Surcel H, Mäkitie O, Andersson S, Laitinen K, Lamberg-Allardt C. Maternal vitamin D status determines bone variables in the newborn. J Clin Endocrinol Metab 2010;95: 1749-57.

[81] Schiessl H, Frost HM, Jee WS. Estrogen and bone-muscle strength and mass relationships. Bone 1998;22: 1-6.

[82] Järvinen TL. Novel paradigm on the effect of estrogen on bone. J Musculoskelet Neuronal Interact 2003;3: 374-80; discussion 381.

[83] Ensom MH, Liu PY, Stephenson MD. Effect of pregnancy on bone mineral density in healthy women. Obstet Gynecol Surv 2002;57: 99-111.

[84] Kiel DP, Rosen CJ, Dempster D. Age-related bone loss. In: Rosen CJ, editor. Primer on the Metabolic Bone Diseases and Disorders of Mineral Metabolism. Washington, D.C., USA: American Society for Bone and Mineral Research; 2008, p. 98-102.

[85] MacKelvie KJ, Petit MA, Khan KM, Beck TJ, McKay HA. Bone mass and structure are enhanced following a 2-year randomized controlled trial of exercise in prepubertal boys. Bone 2004;34: 755.

[86] MacKelvie KJ, Khan KM, Petit MA, Janssen PA, McKay HA. A school-based exercise intervention elicits substantial bone health benefits: a 2-year randomized controlled trial in girls. Pediatrics 2003;112: e447.

[87] Kriemler S, Zahner L, Puder JJ, Braun-Fahrländer C, Schindler C, FarpourLambert NJ, Kränzlin M, Rizzoli R. Weight-bearing bones are more sensitive to physical exercise in boys than in girls during pre- and early puberty: a crosssectional study. Osteoporos Int 2008;19: 1749-58.

[88] Ashizawa N, Nonaka K, Michikami S, Mizuki T, Amagai H, Tokuyama K, Suzuki M. Tomographical description of tennis-loaded radius: reciprocal relation between bone size and volumetric BMD. J Appl Physiol 1999;86: 1347-51.

[89] Sievänen H. Hormonal influences on the muscle-bone feedback system: a perspective. J Musculoskelet Neuronal Interact 2005;5: 255-61. 
[90] Davis R, Sanborn C, Nichols D, Bazett-Jones DM, Dugan EL. The effects of whole body vibration on bone mineral density for a person with a spinal cord injury: a case study. Adapt Phys Activ Q 2010;27: 60-72.

[91] Rittweger J, Beller G, Armbrecht G, Mulder E, Buehring B, Gast U, Dimeo F, Schubert H, de Haan A, Stegeman DF, Schiessl H, Felsenberg D. Prevention of bone loss during 56 days of strict bed rest by side-alternating resistive vibration exercise. Bone 2010;46: 137-47.

[92] Abercromby AF, Amonette WE, Layne CS, McFarlin BK, Hinman MR, Paloski WH. Vibration exposure and biodynamic responses during whole-body vibration training. Med Sci Sports Exerc 2007;39: 1794-800.

[93] Nikander R, Sievänen H, Heinonen A, Kannus P. Femoral neck structure in adult female athletes subjected to different loading modalities. J Bone Miner Res 2005;20: 520-8.

[94] Umemura Y, Ishiko T, Yamauchi T, Kurono M, Mashiko S. Five jumps per day increase bone mass and breaking force in rats. J Bone Miner Res 1997;12: 1480-5.

[95] Cullen DM, Smith RT, Akhter MP. Bone-loading response varies with strain magnitude and cycle number. J Appl Physiol 2001;91: 1971-6.

[96] Bass SL, Naughton G, Saxon L, Iuliano-Burns S, Daly R, Briganti EM, Hume $\mathrm{C}$, Nowson C. Exercise and calcium combined results in a greater osteogenic effect than either factor alone: a blinded randomized placebo-controlled trial in boys. J Bone Miner Res 2007;22: 458-64.

[97] Iuliano-Burns S, Saxon L, Naughton G, Gibbons K, Bass SL. Regional specificity of exercise and calcium during skeletal growth in girls: a randomized controlled trial. J Bone Miner Res 2003;18: 156-62.

[98] Ackerman KE, Nazem T, Chapko D, Russell M, Mendes N, Taylor AP, Bouxsein ML, Misra M. Bone microarchitecture is impaired in adolescent amenorrheic athletes compared with eumenorrheic athletes and nonathletic controls. J Clin Endocrinol Metab 2011;96: 3123-33.

[99] Berry SD, Miller RR. Falls: epidemiology, pathophysiology, and relationship to fracture. Curr Osteoporos Rep 2008;6: 149-54.

[100] Mion LC, Gregor S, Buettner M, Chwirchak D, Lee O, Paras W. Falls in the rehabilitation setting: incidence and characteristics. Rehabil Nurs 1989;14: 1722.

[101] Gillespie LD, Robertson MC, Gillespie WJ, Lamb SE, Gates S, Cumming RG, Rowe $\mathrm{BH}$. Interventions for preventing falls in older people living in the community. Cochrane Database Syst Rev 2009: CD007146.

[102] Komi PV, Fukashiro S, Jarvinen M. Biomechanical loading of Achilles tendon during normal locomotion. Clin Sports Med 1992;11: 521.

[103] Giddings VL, Beaupre GS, Whalen RT, Carter DR. Calcaneal loading during walking and running. Med Sci Sports Exerc 2000;32: 627.

[104] Finni T, Komi PV, Lepola V. In vivo human triceps surae and quadriceps femoris muscle function in a squat jump and counter movement jump. Eur J Appl Physiol 2000;83: 416.

[105] Belanger M, Stein RB, Wheeler GD, Gordon T, Leduc B. Electrical stimulation: can it increase muscle strength and reverse osteopenia in spinal cord injured individuals? Arch Phys MEd Rehabil 2000;81: 1090.

[106] Ensrud KE, Ewing SK, Taylor BC, Fink HA, Stone KL, Cauley JA, Tracy JK, Hochberg MC, Rodondi N, Cawthon PM, Group SoOFR. Frailty and risk of falls, 
fracture, and mortality in older women: the study of osteoporotic fractures. J Gerontol A Biol Sci Med Sci 2007;62: 744-51.

[107] Turner CH. Exercise as a Therapy for Osteoporosis: The Drunk and the Street Lamp, Revisited. Bone 1998;23: 83-85.

[108] Chaganti RK, Parimi N, Lang T, Orwoll E, Stefanick ML, Nevitt M, Lane NE, Group OFiMMS. Bone mineral density and prevalent osteoarthritis of the hip in older men for the Osteoporotic Fractures in Men (MrOS) Study Group. Osteoporos Int 2010;21: 1307-16.

[109] Felson DT, Zhang Y, Hannan MT, Naimark A, Weissman B, Aliabadi P, Levy D. Risk factors for incident radiographic knee osteoarthritis in the elderly: the Framingham Study. Arthritis Rheum 1997;40: 728-33.

[110] Radin EL, Paul IL, Rose RM. Role of mechanical factors in pathogenesis of primary osteoarthritis. Lancet 1972;1: 519-22.

[111] Kontulainen S, Sievänen H, Kannus P, Pasanen M, Vuori I. Effect of longterm impact-loading on mass, size, and estimated strength of humerus and radius of female racquet-sports players: a peripheral quantitative computed tomography study between young and old starters and controls. J Bone Miner Res 2002;17: 2281-9.

[112] Kelley GA, Kelley KS. Dropouts and compliance in exercise interventions targeting bone mineral density in adults: a meta-analysis of randomized controlled trials. J Osteoporos 2013;2013: 250423.

[113] Kothawala P, Badamgarav E, Ryu S, Miller RM, Halbert RJ. Systematic review and meta-analysis of real-world adherence to drug therapy for osteoporosis. Mayo Clin Proc 2007;82: 1493-501. 